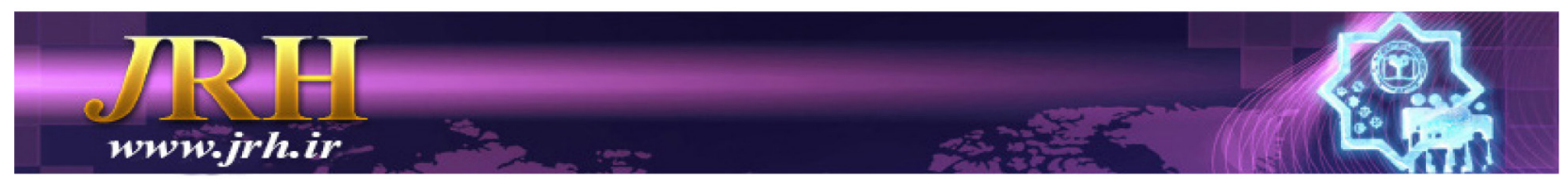

\title{
Psychometric characteristics of type-D personality scale and comparision type-D personality among uniersity students \\ Ehda Zoljanahi ${ }^{1}$, Maryam Vafaie ${ }^{2}$
}

\author{
Journal of Research \& Health \\ Social Development \& Health Promotion \\ Research Center \\ Vol. 7, No. 1, Jan \& Feb 2017 \\ Pages: $545-550$ \\ DOI: 10.18869/acadpub.jrh.7.1.545 \\ Original Article
}

1. Correspondence to: Department of Sport Psychology, School of Humanities, International Imamreza University of Mashhad, Mashhad, Iran

Email: abedifateme55@yahoo.com

2. Department of Psychology, Faculty of Educational Sciences and Psychology, Tarbiat Modares University, Tehran, Iran

Received: 30 Des 2013

Accepted: 16 May 2014

How to cite this article: Zoljanahi E, Vafaie M. Psychometric characteristics of type-D personality scale and comparision type-D personality among uniersity students. $J$ Research Health2017; 7(1): 545- 550.

\begin{abstract}
The purpose of this study was to perform the psychometric characteristics of type-D personality scale and comparision type-D personality among males and females in an Iranian normal population. The method used in the population was survey; containing 1348 students from universities . Of them, 400 participants with master's degree were randomly selected based on the Cocheran's formula (259 males and 141 females).The data collection tool was type-D personality scale. The results showed that the type-D personality scale had suitable reliability and ten items had acceptable validity in the normal community. Therefore, according to the results, only ten of its items can be used in Iranian community. In addition to these findings, this study showed that type-D personality rate and the negative affect were significantly higher in males than in females.
\end{abstract}

Keywords: Factor Analysis, Questionnaire, Student, Type-D Personality

\section{Introduction}

In regard to the relationship between stress and health, studies show that psychological factors have a relationship with previous events and progress of cardiovascular diseases [1]. One of the factors proposed in recent years is the moderating role between health and stress is type-D personality or distressed type [2]. Type-D personality which is defined by the interaction between two fixed and general features of negative affect and social inhibition. Negative affect is determined via tendency to experience of negative feelings over time and situations, but social inhibition is determined by tendency to inhibi the expression of these emotions in social interactions [3,4]. Denollet et al. [2,5] in a 6-10 year follow-up study on patients with coronary heart disease showed that type-D personality is a significant predictor of cardiovascular and non-cardiovascular events such as myocardial infarction, cardiac death, cancer, vital fatigue signs and depressive affect independently of other factors. Type-D personality scale (DS14) was designed by Denollet [6] in 2005 including two subscales of negative affect with 7 items and social inhibition with 7 items. The internal consistency of this scale was calculated by Denollet [6] as 0.88 for negative affect subscale and 0.86 for social inhibition subscale showing a high internal consistency. Also, the results of factor analysis of negative affect and social inhibition subscales using the principal components and the results of correlation method with NEO Five Factor Inventory (NeoFFI) designed by Denollet support the construct validity and convergence of subscale of negative affect and social inhibition subscale [6]. Persian 
version of this questionnaire was prepared by Bagherian et al. [7] and its psychometrics was conducted on 176 Iranian participants with acute myocardial infarction. Cronbach's alpha was 0.84 for negative affect and 0.86 for social inhibition subscale. The content validity of this scale was investigated by 15 psychologists and psychiatrists using the six-point Likert scale for items and tenpoint Likert scale for the whole scale. The results showed high and favorable reliability of this scale. Construct validity of the subscales was approved through correlation with Eysenck Personality Questionnaire and its neuroticism $(r=0.65)$ and extraversion $(r=0.65)$ subscales. In Asgari et al. research [8] to determine the reliability of DS14 in Iranian participants (200 male and female students), Cronbach's alpha and split half were 0.85 and 0.76 , respectively. Asadi Mojreh et al [9]. reported the reliability of negative affect and social inhibition subscales through Cronbach's alpha with 0.79 and 0.81 ; respectively in their study on 275 Iranian male and female students. The construct validity of DS14, which is one of the psychometric properties of this scale, has not been studied on the Iranian normal community yet. It is essential to investigate the psychometric properties of a tool before using it for research and clinical purposes. Given the importance of the role of type-D personality as a significant predictor of coronary heart disease (CHD) and other health damaging factors [2], it is essential to investigate the psychometrics of this questionnaire in Iranian normal community. Another point is the difference between males and females in terms of type-D personality and its components which will be investigated in this study. Denollet [6] compared the results of two factors of negative affect and social inhibition in males and females, and reported a higher level of negative affect in females than in males, and a higher level of social inhibition in males than in females. As noted in this study and other studies $[1,2,5]$ emotional stress has a relationship with coronary heart disease and other health damaging factors, so DS14 factors and its components were analyzed in males and females to investigate the differences between males and females in terms of coronary heart disease and other health damaging factors.

\section{Method}

This study was conducted on a population of 1348 male and female students with Master's degree in the Mashhad universities, the northeast of Iran. Based on preliminary results, a standard deviation (SD) of 12.2 points was obtained for the features of type-D personality with a reliability of $95 \%$ and by assigning one point error based on Cochran's formula; the number of participants are calculated to consist of: 398 .

Finally, 400 participants were randomly selected from Master's classes.

Considering the fact that $35 \%$ of the population was female and $65 \%$ was male, this male:female ratio was considered, and 141 females and 259 males formed the study sample. In this study, before administering the DS14 in the final sample, it was translated from English to Persian by experts, then the accuracy of translation was evaluated in a pilot study in which 31 students participated and filled out the questionnaire, the respondents stated their views about the content and were asked about the content and purpose of some items. After clearing the ambiguous points, the original text and the translated version were compared with each other. Then by considering the preliminary results of implementation and translation challenges, the scale was revised and accommodate to Iranian culture by experts. Finally, the final version of the scale was conducted on a sample group.

DS14 was designed by Denollet in 2005 and includes negative effect and social inhibition subscales [6]. Negative affect has a relationship with dysphoria, worry and irritability but social inhibition is associated with discomfort in social interactions, reticence and lack of social poise [6]. There are 7 items in negative affect subscale, and 7 in social inhibition subscale. Each participant answers the items based on a 5-point Likert scale (true, partially true, not true not false, partially false and false). Scoring is reversed in the first and third items. Thus the score of each subject ranges from 0 to 28 for each subscale, and from 0 to 56 for the 
whole scale. The internal consistency of this scale was calculated by Denollet [6] as 0.88 for negative affect subscale and 0.86 for social inhibition subscale, showing a high internal consistency. Denollet [6] reported construct validity of negative affect and social inhibition subscales through factor analysis results using the principal components, and that items 3,1,7 and 4 are associated with dysphoria, items 2 and 12 are associated with worry and items 5 and 9 are associated with irritability. Factor analysis of 7 items in social inhibition subscale showed that items 6,8 and 14 are associated with discomfort in social interactions, items 10 and 11 are associated with reticence and items 1 and 3 are associated with lack of social poise. Also, the construct validity of negative affect and social inhibition subscales in DS14 was confirmed [6] using correlation with Neo-FFI via the neuroticism $(\mathrm{r}=0.59)$ and extroversion $(r=0.68)$ subscales.

\section{Results}

Factor analysis was used to investigate the construct validity of the scale. Factor analysis was conducted using principal components along with varimax rotation to determine the adequacy of sample size Kaiser-Meyer-Olkin $(\mathrm{KMO}=0.848)$ and Bartlett test (Bartlett's test of sphericity $=642.1656)$ at the significance level $(p=0.001)$. The total amount of variance explained by two factors (negative affect and social inhibition) equals 53.568. Factor analysis using principal components led to ten items of which seven belong to the first factor (negative affect) with validity of $\alpha=0.83$ and they are the same items approved by Denollet's scale .The social inhibition as the second factor and with the validity of $\alpha=0.63$ contains items 3,10 and 1 and has 4 items less than the second factor of Denollet's scale because it was not approved in Iranian subjects. The validity of the whole scale was $\alpha=0.79$. The results of this analysis are presented in Table 1.

Cronbach's alpha coefficient was calculated to assess internal consistency of the scale, and can be seen in Table 2 .

\begin{tabular}{ccc}
\multicolumn{3}{c}{ Table 1 Load factor of items in double factors } \\
\hline Factors-items & Factor 1 & Factor 2 \\
\hline 5 & 0.75 & \\
13 & 0.73 & \\
9 & 0.72 & \\
4 & 0.68 & \\
12 & 0.67 & \\
7 & 0.66 & \\
2 & 0.57 & -0.82 \\
1 & & -0.78 \\
3 & & 0.54 \\
8 & 0.48 & 0.49 \\
14 & 0.46 & 0.49 \\
16 & 0.39 & -0.48 \\
10 & & \\
11 & &
\end{tabular}

According to the values obtained in the above Table, the scale has a good reliability.

One-way ANOVA was performed on the total sample to explain the difference between males and females in terms of DS14 and its components. In this analysis, gender was considered an independent variable, type-D personality, negative affect and social inhibition were considered dependent variables.

The results of this analysis are presented in Table 3. 
Table 2 Cronbach's alpha coefficients of type-D personality scale and subscales

\begin{tabular}{lcc}
\hline \multirow{2}{*}{ Factor } & \multicolumn{2}{c}{ Statistical indexes } \\
\cline { 2 - 3 } & $\begin{array}{c}\text { Number of } \\
\text { question }\end{array}$ & $\begin{array}{c}\text { Cronbach's alpha } \\
\text { Coefficient }\end{array}$ \\
\hline Type-D personality & 14 & 0.79 \\
Negative affect & 7 & 0.77 \\
Social inhibition & 7 & 0.69 \\
\hline
\end{tabular}

Table 3 Results of one-way ANOVA of type-D personality, negative affect and social inhibition

\begin{tabular}{|c|c|c|c|c|c|c|c|c|c|}
\hline $\begin{array}{l}\text { Variable of } \\
\text { personality }\end{array}$ & & & Mean & $\begin{array}{l}\text { Standard } \\
\text { deviation }\end{array}$ & $\begin{array}{l}\text { Sum of } \\
\text { Squared }\end{array}$ & $\begin{array}{c}\text { Mean } \\
\text { squared }\end{array}$ & $\mathrm{F}$ & $\begin{array}{r}\text { Degree of } \\
\text { freedom }\end{array}$ & Sig. \\
\hline \multirow{2}{*}{$\begin{array}{l}\text { Type-D } \\
\text { personality }\end{array}$} & \multirow{2}{*}{$\begin{array}{c}\text { Between } \\
\text { groups } \\
\text { Within } \\
\text { groups }\end{array}$} & Women & 22.80 & 9.15 & 2214.55 & 2214.55 & \multirow{2}{*}{28.24} & 1 & \multirow{2}{*}{0.000} \\
\hline & & Men & 27.73 & 8.68 & 31208.44 & 78.41 & & 398 & \\
\hline \multirow{2}{*}{$\begin{array}{l}\text { Negative } \\
\text { affect }\end{array}$} & $\begin{array}{l}\text { Between } \\
\text { groups }\end{array}$ & Women & 5.99 & 3.66 & 7864.46 & 7864.46 & \multirow{2}{*}{369.17} & 1 & \multirow{2}{*}{0.000} \\
\hline & $\begin{array}{l}\text { Within } \\
\text { groups }\end{array}$ & Men & 15.27 & 5.05 & 8478.53 & 21.30 & & 398 & \\
\hline \multirow{2}{*}{$\begin{array}{l}\text { Social } \\
\text { behavior }\end{array}$} & $\begin{array}{c}\text { Between } \\
\text { groups }\end{array}$ & Women & 3.90 & 2.84 & 7.92 & 7.92 & \multirow{2}{*}{1.15} & 1 & \multirow{2}{*}{0.283} \\
\hline & $\begin{array}{l}\text { Within } \\
\text { groups }\end{array}$ & Men & 3.60 & 2.48 & 2722.44 & 6.84 & & 398 & \\
\hline
\end{tabular}

The above analysis shows that according to the mean scores of males and females, and the significance levels, type-D personality and negative affect were significantly higher in males than in females.

\section{Discussion}

One of the personality types prone to coronary heart disease is type-D or distressed personality, which has attracted psychologists' attention recently. In the present study, since the type-D Personality scale has not been validated and according to the role of type-D Personality in relation to stress and health, the psychometric properties of this questionnaire have been investigated in Iranian community. In this regard, the evaluation of internal consistency of type-D personality showed that this scale has a good reliability and it accords with the results of Denollet's study [6]. In addition, the construct validity of the questionnaire showed that ten items of questionnaire in Iranian community confirm both negative affect and social inhibition of standard scale of Denollet (DS14); seven items are related to negative affect and they are the same seven points which have been confirmed in Denollet's [6]. The second factor (social inhibition) in comparison with the second factor of Denollet's scale has four items less than it. Thus the factor analysis was not confirmed by Iranian sample. However in this study only one way has been used to assess the validity of the subscales of type-D. Therefore, it is suggested that the validity of subscale in social inhibition is investigated using different methods in next studies. In addition, the scale of Type-D personality was 
validated in the normal Iranian community and it limits the capability of generalization of the results to the population with coronary heart disease and emotional disorders. This study showed that the rate of Type-D Personality and negative affect in men was significantly higher than women. As previously mentioned, emotional stress which is independent than standard risk factors has relationship with the coronary heart disease and other damaging factors. So, the evidence was obtained in this study showing that the vulnerability of males to coronary heart disease and other damaging factors on health are more than in females. Sex differences obtained in the present study showing some differences In mood in males and females; men are more aggressive and stubborn while the women try to avoid the problems [10]. Studies show that, the activity of the sympathetic system and the secretion of the adrenaline hormone in men in response to stressful stimuli is greater than women $[11,12]$. Although the data related to cardiovascular problems is difficult to interpret, but some studies support the idea that sex differences in cardiovascular responses may explain the difference rate in cardiovascular disease and mortality rate in women and men. Sex differences can also be analyzed via inheritance to extraversion. Gray et al [13]. suggested that the genetic characteristics are the aspects of the adrenal and pituitary- hypothalamus which can provide a mechanism for inheritance to the extraversion. Gary's reward sensitivity theory [13] hypothesized that high levels of adrenacorticotropic hormones (adrenaline and noradrenalin) and corticosteroid is associated with high anxiety. In this regard Kudila et al. (14) provided the evidences that the responses of adrenal, hypothalamic-pituitary axis in men to stress is higher than in women. The abovementioned evidences strongly support that men are more vulnerable to stress than women and the evidences show the sex differences in the negative affect. The people can be helped in prevention and prognosis of coronary heart diseases, other harmful factors on health and selecting a method for treatment. And in later studies, before the people are envolved to coronary heart diseases, the variables are studied to have relationship to negative affect and type-D. As in this study, the etiology of the outbreak of type-D personality in men and women was investigated in terms of inheritance to stress, so it is suggested that the etiology of incidence of type-D Personality and its components in men and women are investigated socially.

\section{Conclusion}

The results showed that type-D personality scale has suitable reliability and ten items of it have an acceptable validity in normal Iranian community. Considering the results of this study, the only ten items of this scale can be useful to assess the type-D in Iran. The other finding of this study showed that the rate of type-D Personality and negative affect was significantly higher in males than in females.

\section{Acknowledgments}

The authors appreciate those who assisted in conducting the study.

\section{Contribution}

Study design: EZ, MV

Data collection and analysis: EZ, MV

Manuscript preparation: EZ

\section{Conflict of Interest}

"The authors declare that they have no competing interests."

\section{Funding}

The author (s) received no financial support for the research, authorship and/or publication of this article.

\section{References}

1- Denollet J. Personality, emotional distress and coronary heart disease. Eur J Pers 1997; 11(5): 343-58. 2- Pederson SS, Denollet J. Type-D personality, cardiac events, and impaired quality of life: a review. Eur $J$ Cardiovasc Prev Rehabil2003; 10(4): 241-8.

3 - Denollet J, Vaes J, Brutsaert DL. Inadequate response to treatment in coronary heart disease: adverse effects of type-D personality and younger age on 5-year prognosis and quality of life. Circulation2000; 102(6): 
630-5.

4- Denollet J. Type-D personality: a potential risk factor refined. J Psychosom Res2000; 49(4): 255-66.

5- Denollet J, Van Heck GL. Psychological risk factors in heart disease what type-D personality is (not) about. $J$ Psychosom Res2001; 51(3): 465-8.

6- Denollet J. Ds14: standard assessment of negative affectivity, social inhibition And type-D personality. Psychosom Med2005; 67(1): 89-97.

7- Bagherian R, Bahrami Ehsan H. Psychometric properties of the Persian version of type-D personality scale (Ds14). Iran J Psychiatry Behav Sci2011;5(2):12-7. 8- Asgary P, Enayati MS, Asgary M, Roshani K. Relationship between responsibility, risk taking, sensation seeking and type-D personality. Thought \& Behavior in Clinical Psychology2011; 5(20):17-24.

9- Asadi Majareh S, Bakhshipour Rodsari A, Poursharifi H. The relationship of type-D personality and its components with perceived stress in students in Tabriz University. Knowledge \& Research in Applied Psychology2015; 14(54): 91-8.

10- Wilson GD, Barrett PT, Iwawaki S. Japanese reactions to reward and punishment: a cross cultural personality study. Pers Individ Dif1995; 19(1):109-12.

11- Perez MN, Fernandez MC, Garcia A, Turpin G, Vila J. Individual differences associated with cardiac defence response: psychophysiological and personality variable. Psychology in Spain 1999; 3(1): 54-62.

12- Caplea A, Seachrist D, Daneshvar H, Dunphy G, Ely D. Noradrenergic content and turnover rate in kidney and heart shows gender and strain differences. $J$ Appl Physiol2002; 92(2): 567-71.

13- Gray JA, Mc Naughton N. The neuropsychology of anxiety:an enquiry in to the function of the septohippocampal system. 2nd ed. Oxford Psychology Series No. 33. Oxford: Oxford University press; 2000.

14- Kudielka BM, Hellhammer J, Hellhammer DH, et al. Sex differences in endocrine and psychological responses to psychological stress in healthy elderly subjects and the impact of a 2-week dehydroepiandrosterone treatment. $J$ Clin Endocrinol Metab1998; 83(5): 1756-61. 